\title{
O POTENCIAL DAS NARRATIVAS COMO RECURSO PARA O ENSINO DE CIÊNCIAS: UMA ANÁLISE EM LIVROS DIDÁTICOS DE FÍSICA*
}

\author{
Narratives potential as a resource to Science teaching: \\ an analysis of Physics textbooks
}

\author{
Ruth Marina Lemos Ribeiro ${ }^{1}$ \\ Isabel Martins ${ }^{2}$
}

Resumo: Neste artigo discutimos o potencial das narrativas no ensino de Ciências, por meio da análise de quatro versões da história de Arquimedes e a coroa do Rei Hierão, publicadas em livros didáticos de Física. Nossas análises consideraram uma visão ampliada da narrativa como elemento estruturador do pensamento e disseminador da cultura cientifica. Com base em um modelo de análise adaptado da Sociolingüística, discutimos a estrutura e a função de elementos constitutivos do gênero narrativo, estabelecendo como estes elementos permitem a contextualização necessária à interpretação da história para fins didáticos. Mediante as análises, argumentamos que as narrativas podem desempenhar importante papel na construção de imagens sobre a ciência e sobre a atividade científica. Neste trabalho, mostramos como estruturas específicas da narrativa cumprem a função de esclarecer e organizar idéias, e como tal organização viabiliza a inclusão das narrativas como mais uma alternativa para o ensino de Ciências.

Palavras-chave: Narrativas. Ensino de Física. Livro didático. Natureza da ciência.

\begin{abstract}
In this paper we discuss the potential of narratives in science teaching through an analysis of four versions of the story of Archimedes and King Heron's crown, as published in four Brazilian Physics textbooks. Our analyses consider narratives as structuring elements of thinking and instrumental for the dissemination of scientific culture. Based upon an analytical model from Sociolinguistics, we discuss the structure and function of elements, which are constitutive of the narrative genre and establish how they allow the necessary contextualisation for interpreting the story for didactic purposes. We argue that narratives can play an important role in constructing images of science and of scientific activity. We also show how specific narrative structures clarify and organise ideas, and how such organisation makes of narratives a viable alternative for science teaching.
\end{abstract}

Key words: Narratives. Physics education. Textbooks. Nature of science.

\footnotetext{
*Artigo vinculado a Ribeiro (2000).

${ }^{1}$ Mestre em Educação; professora assistente, Centro Universitário Una; Escola Municipal Geraldo T. da Costa, Secretaria Municipal de Educação (SMED). Belo Horizonte, MG. <ruth.marina@una.br>

${ }^{2}$ Doutora em Educação; professora adjunta; Programa de Pós-Graduação em Educação em Ciências e Saúde, Núcleo de Tecnologia Educacional para a Saúde, Universidade Federal do Rio de Janeiro (NUTES/UFRJ). Rio de Janeiro, RJ. <isabelmartins@ufrj.br>. Apoio parcial CNPq.

${ }^{1}$ Rua Ouro Preto, 1143/703

Belo Horizonte, MG

30.170-041 
Ribeiro, R. M. L.; Martins, I.

\section{Introdução}

A literatura mais recente sobre currículos vem apontando uma tendência de se incluir e valorizar o uso de narrativas como recurso didático em sala de aula, não apenas nas aulas de línguas. Essa tendência é particularmente significativa para as disciplinas científicas, conforme argumentam Norris et al. (2005), Millar e Osborne (1998) e Doll Jr. (1997). Para estes autores, as narrativas deixam de ter um papel secundário como, por exemplo, variar a rotina do trabalho em sala de aula, e se constituem em eixos estruturadores de programas curriculares, favorecendo a apresentação de conteúdos científicos e de idéias sobre a Natureza da Ciência num contexto social, histórico e cultural mais amplo.

Norris et al. (2005) descrevem a narrativa como importante ferramenta para a Educação em Ciências, destacando seu potencial para organizar a apresentação dos conteúdos, facilitar a memorização e a compreensão, e aumentar o interesse dos alunos. Doll Jr. (1997, p. 185), afirma que "o diálogo é a condição si ne qua non de todo o processo". Mais adiante, completa: "O modo narrativo requer interpretação. Uma boa estória desafia o leitor a interpretar, a iniciar um diálogo com o texto. Numa boa estória existe exatamente a quantidade suficiente de indeterminação para incitar o leitor ao diálogo". Ao criticar a "ênfase excessiva no conteúdo que [...] limita o estudo de componentes tais como a natureza da ciência, o papel da evidência científica e as maneiras pelas quais os cientistas justificam seu conhecimento", Millar e Osborne (1998) defendem a idéia de que a educação científica deveria fazer uso muito maior de uma das mais potentes e penetrantes maneiras de se comunicar idéias: a forma narrativa. Além disso, afirmam que os currículos de Ciências deveriam ser estruturados tomando-se por base um conjunto de estórias que explicam e descrevem como o mundo funciona.

No Brasil, o caminho apontado pelos Parâmetros Curriculares Nacionais/Ensino Médio (PCN/EM) e pelas Diretrizes Curriculares aponta para a valorização e resgate da importância não apenas da linguagem mas, também, da interdisciplinaridade e da contextualização dos conteúdos como princípios pedagógicos estruturadores do currículo. Um dos veículos que permitem este diálogo entre os vários conteúdos, por meio da linguagem, sem dúvida, é a narrativa. Mais especificamente, no Ensino de Ciências, narrativas de episódios que se relacionam à História da Ciência permitem resgatar um diálogo existente, mas quase sempre ignorado, entre a atividade científica e outras atividades humanas, "[...] que pode ser de questionamento, de negação, de complementação, de ampliação, de iluminação de aspectos não distinguidos" (BRASIL, 1998, p. 25). É esse diálogo que estabelece as relações entre os diversos conteúdos, e que as narrativas permitem reconstruir. Nesse sentido a narrativa pode assumir um papel de articulação de um conhecimento mais específico com idéias mais gerais.

Neste trabalho analisamos, portanto, o potencial das narrativas no Ensino de Ciências. Considerando seu papel estruturante no desenvolvimento de atividades de ensino em sala de aula, bem como seu caráter de materialização do discurso científico escolar (MARTINS, 2006), elegemos o livro didático como contexto empírico para nossas análises. Nossas próprias implicações profissionais justificam a escolha de livros didáticos de Física para uma inspeção mais detalhada. Para tanto, estabelecemos um conjunto de categorias analíticas, baseadas em estudos de narrativas em diversos campos do conhecimento e sua relação com o ensino, utilizando-as para analisar aspectos do seu potencial didático. 
O potencial das narrativas como recurso para o ensino...

\section{Compreendendo as narrativas e seu papel: contribuições da Psicologia, Antropologia e Sociolingüística}

Tradicionalmente, as narrativas têm sido discutidas no âmbito dos Estudos Literários, que distinguem seus tipos mais comuns - o romance, a novela, o conto e a crônica -, e conceituam seus elementos estruturais - o enredo, os personagens, o tempo, o espaço e o narrador. (VILARES GANCHO, 1997). No entanto, o interesse pelo seu estudo se estende por outras áreas do conhecimento, tais como a Antropologia, a Psicologia e a Sociolingüística. Destacamos, a seguir, contribuições para a análise de narrativas advindas destas áreas.

Com a Psicologia, foi possível perceber a narrativa como algo mais do que um gênero literário. Diferentes autores, como Edwards (1997) e Bruner (1986), por exemplo, apresentam a narrativa como uma das formas básicas pelas quais o homem se expressa, estrutura e organiza seu pensamento. Além da narrativa, a literatura em Psicologia tem apresentado a argumentação como outra forma básica de estruturação do pensamento humano. Bruner (1986), por exemplo, faz uma discussão bem ampla sobre o que ele considera "os dois modos de pensamento": o paradigmático (ou lógico-científico) e o narrativo. Ambos permitem ao homem organizar a experiência, descrever o mundo, entender como ele funciona, se comunicar, sendo muito eficientes na transmissão de idéias e no convencimento. O que as difere basicamente é do que elas convencem, além de algumas propriedades que as caracterizam.

A forma de pensamento lógico-científico ou paradigmático estabelece relações gerais reguladas por princípios próprios de logicidade que permitem dizer se suas conclusões, baseadas em algumas premissas, são falsas ou verdadeiras, independentemente de contexto ou outras condições externas. O racional que regula sua estrutura é a lógica. É expressa em uma linguagem que lança mão de operadores lógicos, baseada em princípios de consistência e de não-contradição, utilizada, sobretudo, na argumentação lógica e na expressão de teorias científicas, a serem testadas contra a realidade que descrevem. É basicamente a linguagem científica dos meios acadêmicos.

Diferentemente da forma paradigmática, a forma narrativa é característica das boas histórias e não está sujeita a verificações ou provas, mas a interpretações. É característica da narrativa uma certa liberdade de expressão, um descomprometimento relativo, que Martin e Brouwer (1991), num artigo no qual defendem o uso da narrativa no ensino de Ciências, expressam do seguinte modo: "ao contrário do modo paradigmático, uma boa narrativa pode se valer de exageros óbvios, paradoxos, ambigüidade ou mesmo contradição, para atingir seu significado" (p. 711).

Bruner (1990) explicita, pelo menos, três propriedades fundamentais das narrativas. A primeira, e talvez mesmo a principal, que nos permite identificá-la, é sua seqüencialidade inerente. Uma narrativa compõe-se de uma seqüência cronológica de eventos, acontecimentos que envolvem personagens ou atores (seres humanos ou não), reais ou imaginários. É a seqüência de suas sentenças, e não a falsidade ou veracidade de cada uma delas individualmente que determina sua configuração e lhe dá significado. Existe uma relação entre cada um dos eventos que compõem a narrativa e a narrativa como um todo. É esta relação que estrutura a narrativa e a partir da qual se interpretam os fatos narrados. Outro aspecto das narrativas é que "elas podem ser reais ou imaginárias, sem perder seu poder como história" (BRUNER, 1990, p. 44). Elas tratam da vida, sem necessariamente serem fiéis a ela. Boas histórias nem sempre 
relatam fielmente a verdade, mas têm credibilidade. Na narrativa, são relatados fatos, acontecimentos, cuja veracidade não pode ser comprovada, mas que são verossímeis, "parecidos com a vida". Talvez seja este um dos pontos-chave do seu poder de convencimento. Narrativas são julgadas pela sua verossimilhança, enquanto teorias científicas o são pela sua verificabilidade ou comprobabilidade. Finalmente, um terceiro aspecto crucial da narrativa é que esta precisa ter algo que a justifique. Relatos produzidos sobre fatos e comportamentos corriqueiros estão fadados à monotonia, ao desinteresse de seu público-alvo. Não se produzem relatos sobre fatos e comportamentos ordinários, esperados, ditos normais, tendo como referencial uma cultura que é compartilhada pelo autor e pelo interlocutor. Nas palavras de Bruner (1997, p. 140): "Não é qualquer seqüência de acontecimentos que é digna de ser relatada. Ela (a narrativa) se justifica pelo fato de que a seqüência de acontecimentos seja uma violação da canonicidade". Ou ainda: "A função da história é encontrar um estado intencional que [...] torna compreensível um desvio de um padrão cultural canônico" (BRUNER, 1990, p. 49).

Estas idéias de Bruner (1990) têm inspirado um grande número de estudos acerca da utilização de narrativas em situações didáticas. Entre elas, destacamos as propostas de Egan $(2005,2000)$ que, caracterizando a educação como uma recapitulação das formas de compreensão e de organização cultural da humanidade, situa a narrativa como elemento essencial para a estruturação de um modelo curricular.

Edwards (1997), numa discussão sobre a questão da memorabilidade nas narrativas, relaciona essa característica da narrativa, de representar explicações para uma violação da canonicidade a uma outra abordagem do ponto de vista da Psicologia: a teoria dos scripts, de Schank, cuja definição Cortazzi (1993), numa revisão sobre modelos psicológicos das narrativas, recupera de Schank: "estruturas de conhecimento que descrevem eventos rotineiros, seqüências predeterminadas de ações que definem uma situação" (SCHANK, 1975 apud CORTAZZI, 1993, p. 63). Por exemplo, "fazer um pedido num restaurante" caracteriza uma seqüência de eventos estereotipados. Esta situação é composta por uma seqüência de ações conhecidas e adotadas por qualquer protagonista que dela participe. É quase um ritual, no qual cada ação corresponde a um passo a ser seguido numa determinada ordem. Neste caso, a seqüência é tipicamente a seguinte: entrar, escolher uma mesa, sentar-se, esperar um garçom (ou chamar por um), olhar o cardápio, fazer o pedido. Qualquer pessoa, inserida numa cultura em que ir a restaurantes do tipo à la carte seja uma ação rotineira, que veja uma pessoa seguindo estes passos, reconhecerá o script 'fazer um pedido num restaurante'. Por outro lado, qualquer pessoa inserida nesse mesmo contexto cultural, que entre num restaurante, saberá como se comportar, ou seja, saberá qual é o script. Na teoria dos scripts de Schank, narrativas são vistas como uma série de elos causais, ou seja, cada um dos eventos relatados numa narrativa guarda uma relação não apenas uns com os outros, mas também com o todo. Quando uma seqüência comum (script) está presente na narrativa, ela ajuda no estabelecimento dessas relações. Mais tarde, se houver necessidade de recuperar os eventos narrados, a presença dos scripts será bastante útil, pois, de alguma forma, facilita a elaboração de associações, na medida em que estas representam uma seqüência conhecida de ações a serem realizadas.

Referências a aspectos e questões culturais envolvidas nas narrativas são mais exploradas na Antropologia, que "estuda as narrativas em termos dos padrões culturais de costumes, crenças, valores, atuação e contexto social de narração", Cortazzi (1993, p. 100). Deste ponto de vista, a narrativa é uma forma de expressão comum a todas as culturas, embora 
O potencial das narrativas como recurso para o ensino...

existam vários subgêneros nos quais a narrativa pode aparecer, por exemplo: histórias, anedotas, epopéias ou parábolas.

No contexto dos estudos antropológicos, Cortazzi (1993) aponta, como a função mais importante da narrativa, definir e expressar categorias culturais básicas no compartilhamento de experiências individuais. Em outras palavras, nesse contexto, a narrativa é vista como forma de expressão dos valores culturais de um determinado grupo social e reflete tais valores, contribuindo para sua preservação e difusão. Além disso, Andrews (1989) chama a atenção para o fato de que ao mesmo tempo em que a narrativa, do ponto de vista cultural, é responsável pela preservação e divulgação de valores, ela também desempenha importante papel no estabelecimento de novos valores.

Assim como a Psicologia e a Antropologia, também a Sociolingüística tem se ocupado do estudo das narrativas. Especificamente no contexto sociolingüístico, vale a pena mencionar o trabalho seminal de Labov (1967 apud CORTAZZI, 1993), que desenvolveu um modelo de análise que relaciona características textuais e funcionais de elementos constituintes da estrutura interna da narrativa (CORTAZZI, 1993). Seu objetivo inicial era "[...] examinar propriedades estruturais formais de narrativa em relação com suas funções sociais" (CORTAZZI, 1993, p. 43).

O modelo proposto por Labov (1972 apud CORTAZZI, 1993) estrutura a narrativa em seis elementos: abstract, orientação, complicação, avaliação, resolução e coda. O abstract, opcional, é uma introdução que, em geral, resume a questão a ser tratada, indicando ao leitor do que se trata o material que ele tem em mãos. A orientação localiza a questão a ser tratada, dando informações sobre tempo, pessoas, lugares e situação, necessárias, segundo o autor, para a compreensão dos eventos narrados. A complicação, basicamente o conteúdo da narrativa, descreve os fatos acontecidos. A avaliação, geralmente uma interrupção da narrativa propriamente dita, "[...] revela a atitude do narrador frente à narrativa, enfatizando a importância relativa de algumas unidades narrativas em oposição a outras" (CORTAZZI, 1993, p. 46). A resolução, em geral, apresenta a solução para um conflito na narrativa, e a coda, opcional, encerra a narrativa, retornando os ouvintes ao momento presente.

Resumidamente, os elementos que estruturam a narrativa podem ser identificados como respostas às seguintes sistematizadas na Tabela 1:

Tabela 1. Elementos que estruturam a narrativa (LABOV, 1972* apud CORTAZZI, 1993, p. 45).

\begin{tabular}{ll}
\hline $\begin{array}{c}\text { Elementos constituintes } \\
\text { da estrutura interna da narrativa }\end{array}$ & \multicolumn{1}{c}{ Questões às quais se referem } \\
\hline Abstract & Do que se trata? \\
Orientação & Quem? Quando? Onde? O quê? \\
Complicação & Então, o que aconteceu? \\
Avaliação & E então? \\
Resolução & Finalmente, o que aconteceu? \\
Coda & Fechamento \\
\hline
\end{tabular}

* sugerimos a leitura do texto original (LABOV, 1972). 
Ribeiro, R. M. L.; Martins, I.

\section{Narrativas no ensino de Ciências: ampliando nossa visão}

No campo da Educação em Ciências, alguns trabalhos discutem, sob diferentes pontos de vista, o potencial didático das narrativas. Entre eles, destacamos os estudos de Milne (1998), que apontam para a contribuição das narrativas da História da Ciência na transmissão de uma noção particular de cultura da ciência, podendo ser exploradas para iniciar o aluno na cultura científica, descrevendo e situando, social, política e historicamente, os processos de produção do conhecimento científico, como algumas idéias vão cedendo lugar a outras ou como vão se incorporando ao conhecimento já existente. Milne (1998) descreve, ainda, como tais narrativas representam os cientistas como "heróis e seu trabalho como transcendendo as limitações de sua época e iluminando as épocas futuras" (p. 178). Para essa autora, o herói da ciência não é um herói de ações, típico das aventuras infantis ou mitológicas, mas sim um "herói do pensamento", "um descobridor da verdade", determinado, corajoso, como a maioria dos heróis. Assim como o herói de ações enfrenta perigos, arriscando sua própria vida para atingir uma conquista, o herói da Ciência desafia o conhecimento de sua época, independentemente das possíveis conseqüências que isso possa ter para seu bem-estar. Galileu é um exemplo: ele questionou o conhecimento vigente em sua época, de que a Terra era o centro do Universo, e por defender essa e outras idéias, foi condenado à prisão domiciliar até o fim de sua vida. Esta descrição corresponde a um estereótipo já estabelecido, que nem sempre corresponde à verdade ou é comprovado pelos fatos da vida real, mas que é verossímil. Tais relatos, a exemplo da mídia - em particular dos filmes -, valem-se deste estereótipo e de sua verossimilhança, colaborando, dessa maneira, para a difusão e a manutenção de tal imagem do cientista. Essa cultura do cientista herói, por sua vez, contribui para reforçar a idéia de que a ciência é muito mais um resultado de alguns indivíduos, que trabalham necessariamente isolados, do que um produto que resulta do trabalho de várias pessoas, que tanto podem cooperar ou concorrer entre si.

Por outro lado, Ogborn et al. (1996) discutem como as narrativas podem ser utilizadas como recurso para recontextualizar o conhecimento científico de forma a atender interesses e necessidades de diferentes audiências, em particular dos estudantes. Entre as várias formas possíveis para as narrativas, as parábolas são particularmente comuns no âmbito do ensino de Ciências, especialmente, para a divulgação de idéias sobre a natureza da ciência (OGBORN et al., 1996). Parábolas são episódios que encerram uma "lição de moral". Benefícios do uso de narrativas no ensino são também destacados nos trabalhos de Barbosa-Lima, Alves e Ledo (1997).

No caso do ensino de Ciências, entendemos que as narrativas relativas à História da Ciência, encontradas nos materiais didáticos, podem (ou deveriam) desempenhar, sobretudo, duas funções: informativa e avaliativa. A primeira delas refere-se ao fato de que tais textos existem mesmo para transmitir informações, contar sobre coisas que aconteceram, dar ciência ao leitor de fatos e eventos que se julga importante que ele tenha conhecimento. A outra, avaliativa, refere-se especificamente, nas narrativas examinadas, a eventuais significados que os fatos ali narrados possam ter, normalmente estabelecidos a posteriori, e cujo entendimento exige do leitor um "background" que não se pode assumir que ele tenha.

Embora esta perspectiva não esteja diretamente relacionada a nossa questão de investigação, notamos que a narrativa também é discutida, nas áreas de Educação e de Educação 
O potencial das narrativas como recurso para o ensino...

em Ciências, como um método para investigação em educação, para a formação e para a promoção da reflexão sobre a prática docente (GALIAZZI et al., 2005; GALVÃO, 2005).

Com base nesta revisão, concluímos que, ao ampliar nossa conceitualização de narrativa, podemos melhor caracterizar seu papel na Educação em Ciências. Por exemplo, as classificações dos Estudos Literários nos permitem enxergar textos narrativos de episódios da História da Ciência sob uma outra ótica. Alguns textos podem se assemelhar ao conto no sentido de que, muitas vezes, não apresentam narrativas completas, são curtos e condensam ações num curto espaço de tempo. Outros textos podem ser estruturados em torno de personagens principais como, por exemplo, heróis responsáveis por grandes feitos. Determinados textos podem, ainda, seguir a lógica ficcional de uma história de detetive. As análises dos Estudos Literários nos fornecem uma linguagem de descrição do gênero narrativo, identificando seus principais componentes e auxiliando-nos, conseqüentemente, na comparação de diferentes textos. As considerações advindas das leituras no campo da Psicologia ampliam o significado e a função de textos narrativos, relacionando-os com a estruturação da experiência e a possibilidade de construção de entendimentos. Por outro lado, a contribuição dos estudos da Antropologia ressalta o papel da narrativa na construção e preservação de uma cultura científica. Os elementos propostos nas análises sociolingüísticas de Labov (1972 apud CORTAZZI, 1993) merecem um destaque, pois permitem estruturar análises em função de suas características intrínsecas. Esta visão ampliada será aquela considerada em nossos estudos.

\section{Um exemplo de análise: Arquimedes na banheira}

Em nosso estudo, foram examinados, inicialmente, oito livros-texto de Física para o Ensino Médio, escolhidos dentre aqueles mais freqüentemente adotados pelos professores das escolas da Região Metropolitana de Belo Horizonte. Na maioria dos textos analisados, foi possível perceber que o papel de textos narrativos restringia-se a ilustrações do conteúdo apresentado, em geral concentrando-se em episódios pitorescos que se relacionam à História da Ciência, tais como: a queda simultânea de uma bola de canhão e uma pena, por Galileu; a queda da maçã na cabeça de Newton; o sonho de Kekulé; Arquimedes saindo correndo da banheira, entre outros. Outros tipos de texto encontrados foram biografias de cientistas, históricos da evolução de conceitos, descrições de experimentos. Na maioria das vezes, as narrativas não integram o texto principal das unidades e capítulos. Elas estão no final dos mesmos, após a exposição do conteúdo, em geral sob um título de "leitura complementar ou suplementar". Tal denominação, por si só, compromete o nível de importância atribuída à contribuição dessas histórias para a compreensão dos conteúdos destacados no texto do corpo principal dos capítulos (conceitos, leis gerais, princípios etc).

Dentre os textos didáticos examinados, e a partir do quadro teórico apresentado anteriormente, optamos por analisar um caso exemplar de narrativa de livros didáticos de Física para o Ensino Médio, presente em quatro dos oito livros examinados: a história de Arquimedes e a coroa do Rei Hierão. Foram analisadas quatro narrativas sobre este episódio, extraídas dos seguintes livros: Física para o $2^{\mathbf{0}}$ Grau Mecânica (GUIMARÃES e FONTE BOA, 1998); Os Alicerces da Física (YAMAMOTO, FUKE e SHIGEKIYO, 1998); Física (PARANÁ, 1995); e Curso de Física (MÁXIMO e ALVARENGA, 1992). Estas narrativas serão 
Ribeiro, R. M. L.; Martins, I.

identificadas, daqui por diante, por narrativas 1, 2, 3 e 4, respectivamente. Em nossas análises de natureza qualitativa, que possuem caráter exploratório, buscamos: (i) identificar formas pelas quais narrativas relacionadas à História da Ciência estão inseridas nos textos didáticos; (ii) descrever seus elementos estruturais e funcionais, com base nas categorias do modelo de Labov (1972 apud CORTAZZI, 1993), e (iii) discutir quais aspectos relacionados à Natureza da Ciência estas narrativas sugerem ou reforçam.

\section{A história e suas versões}

A história de Arquimedes e a coroa do Rei Hierão consiste basicamente dos seguintes fatos: um rei, tendo encomendado uma coroa de ouro a um ourives, para cuja execução forneceu o ouro, desconfiou de que havia sido enganado após receber a encomenda. Mais exatamente desconfiou do ourives encarregado do serviço, que teria misturado, ao material fornecido, um pouco de prata, de maneira que a peça pronta apresentava o mesmo peso do material inicialmente fornecido. Arquimedes foi solicitado a, sem danificar a coroa, descobrir se o rei havia sido enganado de fato ou não. Durante um banho, ao ter a idéia do que lhe permitiria solucionar o problema ocorrido, Arquimedes saiu nu, correndo pelas ruas, gritando "Eureca! Eureca!". Em algumas versões analisadas, há ainda a descrição da experiência idealizada e realizada por Arquimedes para resolver o problema.

A narrativa 1 introduz o capítulo que trata de mecânica dos fluidos, e é distinta das demais por apresentar um elemento de dialogicidade, já que é narrada na $1^{a}$ pessoa do singular. Isto sugere a tentativa de uma comunicação mais direta com o leitor, instigando sua curiosidade, chamando-o a pensar e a responder perguntas dirigidas diretamente a ele, por exemplo "Adivinhou qual a tarefa que ele me deu?", além de criar uma expectativa pelo desfecho da história.

Já a narrativa 2 não corresponde a uma introdução a determinado conteúdo, mas representa um encerramento. A localização no final, depois de visto todo o conteúdo, de maneira recortada do texto principal, funciona mais como uma ilustração desse conteúdo, ou como um breve momento de descontração, após várias páginas de cálculos, equações e exercícios. É possível, ainda, especular no sentido de dizer que esta narrativa cumpre a função de acrescentar informações que, de alguma forma, enriquecem o conteúdo principal. Porém, o fato de a narrativa vir destacada do texto principal, pode ter o efeito contrário ao desejado: favorecer a seletividade por parte do leitor, que pode, por exemplo, identificá-lo com pontos que não são geralmente cobrados em avaliações aplicadas cotidianamente.

A narrativa 3 evidencia um recurso de extremo valor pedagógico das narrativas: a possibilidade de trabalhar a história do ponto de vista de sua estrutura interna, dividindo-a em duas ou mais partes, conforme a conveniência e os objetivos que se têm ao narrar a história. No caso específico deste episódio, ao separar a história, têm-se a vantagem de poder separar dois conceitos que se relacionam, porém são distintos: densidade e força de empuxo. Inicialmente, ao destacar que Arquimedes se sentiu mais leve ao entrar na banheira, o texto remete o leitor a uma sensação conhecida de todos, a da leveza experimentada quando se entra na água, e a um conceito físico que será (ou está sendo) estudado. Na segunda parte da história, vincula-se o derramar de água da banheira (outra experiência muito comum no nosso cotidiano) ao conceito de densidade. Ao contrário de prejudicar a seqüência de eventos na história, a divisão 
O potencial das narrativas como recurso para o ensino...

da narrativa em duas partes permitiu, neste caso, distinguir conceitos físicos e, ao mesmo tempo, relacioná-los, identificando-os a episódios facilmente memoráveis.

A narrativa 4 analisada corresponde a três quartos de página de um total de cinco páginas que compõem uma seção, apresentada ao final de um capítulo sobre Hidrostática, intitulada "Um Tópico Especial - para você aprender um pouco mais". O texto que contém esta narrativa está dividido em várias seções, demarcadas por subtítulos. A seção a que se refere o episódio, intitulada "Eureka! Eureka!", articula duas formas discursivas distintas. Inicia narrando o episódio em questão, como nos demais exemplos analisados. Após a exposição do episódio, porém ainda na mesma seção, a forma discursiva deixa de ser narrativa e passa a ter características mais típicas do discurso paradigmático. Em outras palavras, o texto passa a ser organizado em itens ordenados numericamente, que descrevem, cada um, uma etapa da experiência, deixando claro que existe uma hierarquização nos procedimentos relatados, evidenciando um forte apelo para a lógica, mais racional, adequada (e necessária) à solução de um problema, da maneira tipicamente científica.

\section{Composição do texto: o que se pode dizer com base na localização da narrativa em relação ao texto principal}

Como se observa, tomando-se por base a descrição feita anteriormente das quatro narrativas encontradas, não existe uma localização privilegiada, dentro do texto principal, para as mesmas. Esta localização varia, podendo vir no início, no meio ou no fim de um texto que aborda o tópico Hidrostática. Esta variação na localização acaba tendo por conseqüência diferentes funções e papéis para a narrativa dentro do texto principal.

Se ela aparece no início da seção, introduzindo o assunto, como é o caso da primeira e da terceira narrativas, ela pode servir de estímulo ao aluno, motivando-o para o estudo subseqüente, apresentando o assunto de maneira menos formal. No caso particular da primeira narrativa, ela vai mais além: ela representa um desafio. É apresentado um problema de difícil solução, que, generalizando, pode ser apresentado da seguinte forma: descobrir se um determinado objeto (no caso, uma coroa) é constituído de um material puro (ouro), ou se foi misturado outro material (prata) na sua fabricação, sem danificar o referido objeto. Aparentemente, um problema impossível de ser resolvido, pelo menos para quem ainda não conhece o conceito de densidade. A situação fica ainda mais intrigante quando se pensa que o desfecho da história se dá dizendo que Arquimedes teve a idéia que lhe permitiu solucionar o problema ao observar que, à medida que se afundava na banheira, um pouco de água era derramado para fora da mesma.

Em outros casos, como na segunda e quarta narrativas, em que estas aparecem no fim do texto principal, percebe-se que elas cumprem basicamente duas funções: a de exemplificar uma aplicação do que foi estudado ou a de ilustrar o conteúdo abordado. Isso é reforçado, sobretudo, quando o texto aparece recortado do texto principal. Novamente aqui é necessário que a história seja lida e comentada, se queremos que esta tenha uma relação mais significativa com o conteúdo estudado, explicitando como ela de fato mostra uma aplicação prática para os princípios e conceitos recém estudados.

A localização da narrativa, se no início, como introdução ao conteúdo que se quer 
apresentar, ou se no final, depois de estudado o conteúdo, depende do objetivo da inclusão da narrativa. Em posições diferentes, ela atende a objetivos diferentes. O importante é estabelecer uma relação significativa da história com o assunto estudado, o que poderá ser feito de formas diferenciadas, dependendo desta localização e dos objetivos aos quais se deseja atender. Mesmo considerando que os professores têm autonomia para trabalhar com o livro didático e para alterar a seqüência proposta de conteúdos, a divisão entre corpo principal do texto e textos complementares (entre os quais estão as leituras suplementares) pode sugerir uma valorização distinta das informações contidas nestes diferentes blocos de texto.

\section{Formatos típicos de apresentação das narrativas: verossimilhança e convencimento}

As quatro narrativas foram analisadas com respeito às categorias propostas por Labov (1972 apud CORTAZZI, 1993). Nesta análise identificamos elementos componentes da narrativa por meio de características textuais, conforme mostrado no exemplo ilustrado na Tabela 2.

Após a identificação de seus componentes estruturais, discutimos suas funções em relação à narrativa como um todo. Entre elas, destacamos a importância do abstract que, quando bem estruturado, pode servir de estímulo à própria leitura, além de evitar a leitura de um trecho grande (e, às vezes, cansativo) para se saber do que trata o texto que se tem em mãos. Vimos, também, que a orientação ajuda a situar o leitor, proporcionando contextos relevantes que potencialmente colaboram para a compreensão das idéias a serem discutidas. No caso das narrativas analisadas, chamamos especial atenção para as referências à reputação de Arquimedes como homem sábio e o sentido de seu papel social. É na complicação onde se estabelecem as bases do problema que justifica a narrativa. Neste caso, observamos, nas narrativas analisadas, a apresentação de uma relação entre uma questão de ordem prática e a necessidade de sua solução por meios irrefutáveis. Vemos, assim, que os trechos correspondentes às orientações e complicações das narrativas contêm importantes elementos para a discussão de aspectos relacionados a aspectos da natureza da ciência. Já a resolução mostra o resultado dos eventos e das ações narradas, que consistem na solução do problema. Em nossas análises, vimos que é na resolução onde se constrói a vinculação entre eventos, tais como o problema da coroa e a água que entorna durante o banho. Finalmente, na avaliação, chama-se a atenção do aluno exatamente para a importância, o valor e o significado dos fatos narrados e das informações fornecidas dentro de todo um contexto já explicitado na orientação. Nos exemplos analisados, percebemos a valorização da engenhosidade da solução proposta e o destaque dado ao papel da imaginação na resolução do problema.

Percebemos que o modelo proposto por Labov (1972 apud CORTAZZI, 1993), embora originalmente elaborado com base em análises de estórias orais, mostrou-se apto a descrever as narrativas de episódios encontradas nos livros didáticos. Dos elementos estruturais definidos por Labov (1972 apud CORTAZZI, 1993), identificamos que somente as estruturas Abstract e Coda não estão presentes em todos os textos analisados. Por outro lado, os demais elementos (orientação, complicação, resolução e avaliação), que basicamente contêm o enredo, ou seja, as informações que caracterizam uma história em particular, estão presentes em todos 
O potencial das narrativas como recurso para o ensino...

os textos analisados. Isso mostra a adequação do modelo escolhido para este tipo de análise. É importante destacar, ainda, que a estrutura proposta por Labov (1972 apud CORTAZZI, 1993) nem sempre ocorre na seqüência prevista. Contudo, como estas são estruturas funcionais, pode-se especular quanto à razão para estas ausências ou não-linearidades. Por exemplo, narrativas que começam com avaliações, geralmente visam capturar a atenção e despertar o interesse do leitor.

Tabela 2. Exemplo de análise utilizando categorias de Labov (1972 apud CORTAZZI, 1993).

\begin{tabular}{ll}
$\begin{array}{c}\text { Elementos constituintes da } \\
\text { estrutura interna da narrativa }\end{array}$ & \multicolumn{1}{c}{$\begin{array}{c}\text { Narrativa } 1 \\
\left.\text { (GUIMARÃES e FONTE BOA, Física para o } 2^{\circ} \mathrm{grau}\right)\end{array}$} \\
\hline Abstract & Não contém. \\
Orientação & "Eu vivi há dois mil anos atrás, em Siracusa, uma \\
& cidadezinha ao Sul da Itália. Tinha fama de gênio, e, \\
& certamente por isso, Hieron, o tirano da cidade, \\
Complicação & chamou-me para mostrar uma coroa que "parecia" de \\
& ouro puro. Digo que "parecia", pois esse era \\
& justamente o problema: Hieron desconfiava que, \\
& embora o peso da coroa fosse igual ao peso de ouro \\
& que entregara ao ourives, este havia "surrupiado" parte \\
& do ouro, substituindo-o por prata, metal menos nobre e \\
& mais barato. Adivinhou a tarefa que ele me deu? Isso \\
& mesmo: eu teria de descobrir, sem danificar a coroa, se \\
& a desconfiança dele tinha fundamento. E mais: se eu \\
não descobrisse, zás! Cortaria minha cabeça! É fácil \\
imaginar que o problema não me saiu da cabeça \\
durante os dias seguintes; não conseguia me desligar \\
dele nem mesmo ao tomar banho.
\end{tabular}

Avaliação

Resolução

Coda
E foi o que me salvou; justamente num desses banhos, veio-me à mente uma idéia genial:

relacionei a quantidade de água que meu corpo deslocava com o fato de parecer mais leve dentro dela. Daí para a solução era um pulo!

Foi o que fiz: pulei da banheira e, de tão contente, saí gritando pela rua: Eureka! Eureka! (Descobri!

Descobri!). Mas logo notei que as pessoas, embora já acostumadas às minhas distrações, olhavam-me com um grande espanto. Pois não é que, na minha euforia, havia esquecido de me vestir?" 


\section{Verossimilhança e poder de convencimento das narrativas}

Como dito anteriormente, narrativas são julgadas com base em um critério de verossimilhança, ou seja, elas podem ser reais ou imaginárias, sem perder seu poder como história. O episódio em questão, com certeza, é lendário, e as quatro versões analisadas deixam isso claro. Mas o poder de convencimento das narrativas não reside na sua veracidade, mas em quão convincente é a história contada. No âmbito do Ensino de Ciências, não é diferente. Não importa se a história conta fatos realmente acontecidos ou se fantasia sobre eles. O que importa é que, por ser verossímil, ou seja, possível de ser real, ainda que não o seja, ela permite detonar discussões sobre algumas características do processo científico. Ela permite iniciar uma discussão sobre ciência.

No caso em questão, quando se diz que o fato de a história ter sido ou não inventada, ou seja, o mais importante não é se ela é ou não uma lenda. Não se trata de um levantamento histórico, em que determinar se fatos ocorreram ou não pode ser crucial nesta reconstrução. $\mathrm{O}$ interesse nesta história está no que ela pode nos ajudar a ensinar sobre ciência. Nesse sentido, detalhes, como, por exemplo, se os materiais usados na experiência foram ouro e prata, não importam, desde que mantida a coerência interna da história. No entanto, muito provavelmente para preservar sua lógica interna, e nem tanto por a história ter de fato acontecido, ou ter acontecido como hoje a conhecemos, todas as versões divulgadas desta história, nos diferentes livros, refiram-se sempre aos metais ouro e prata. Em outras palavras, esta história muito provavelmente não é verdadeira, mas é verossímil. O que esta história ensina, entre outras coisas, é que os diversos materiais possuem uma propriedade que torna possível, por comparação, descobrir se um determinado objeto é composto de uma substância ("material") pura ou não.

Um dos aspectos que ajudam a compor a verossimilhança das narrativas é a caracterização de personagens e de todo o contexto, típicos dos trechos que correspondem a estruturas de orientação. Isso significa que a história, para ser plausível, depende que seu protagonista tenha um perfil que combine com suas ações durante o desenrolar da história. No exemplo considerado, o protagonista irá apresentar uma solução brilhante para um problema intrigante, misterioso, difícil. E mais, a resolução se dá numa situação inusitada: ele terá sua idéia a partir de uma situação cotidiana, um banho, quando observa um fenômeno corriqueiro, que provavelmente é observado por várias pessoas. A diferença entre o sujeito que vai atribuir a tal situação um significado especial, e qualquer uma das milhares de pessoas que não conseguem ver nada de significativo na água que derrama da banheira à medida que se mergulha nela, é que este personagem tem de ser construído de maneira que suas características (profissão, hábitos, inteligência, histórico de vida etc.) lhe dêem condições de realizar a façanha contada na história. Neste caso, estamos falando de um cientista, inventor, matemático, enfim, uma pessoa brilhante, autor de idéias engenhosas e soluções geniais para os mais diversos problemas. Três das quatro narrativas analisadas fazem questão de reforçar este perfil, sempre antes de mencionar que Arquimedes resolveu o problema, ou teve a idéia durante o banho etc. Na quarta narrativa, esta caracterização acontece fora da mesma, antes dela, nas seções anteriores que compõem o texto no qual se inclui a narrativa. Tem uma página descrevendo quem foi Arquimedes (construindo o personagem da futura narrativa) e outra que lista suas principais invenções. Esta caracterização é essencial para garantir a plausibilidade dos fatos que vêm na se- 
O potencial das narrativas como recurso para o ensino...

qüência. Com isso, criam-se condições mínimas para se dar credibilidade, dentro da história, aos eventos narrados. Exemplos dessa caracterização são os trechos seguintes: “[... ] Arquimedes, que tinha fama de saber tudo [...]" (terceira narrativa); "Tinha fama de gênio $e$, certamente por isso [...]" (primeira narrativa); "O grande cientista e inventor grego [...]"; "[...] sua obra é muito extensa, apresentando outras contribuições notáveis, não só na Física como também na Matemática e na tecnologia"; "[...] as engenhosas invenções de Arquimedes [...]" (retiradas dos trechos que antecedem a quarta narrativa).

Além das etapas de orientação permitirem toda essa construção do personagem e qualificá-lo a desempenhar adequadamente seu papel na história, ela também contribui para preservar e difundir uma imagem do cientista identificada com um estereótipo muito presente no imaginário popular: um sujeito genial, sábio e capaz de oferecer grandes contribuições para diferentes áreas do conhecimento humano. Ao apoiar-se sobre esta imagem, que corresponde à descrição de um perfil que faz parte da cultura de uma certa comunidade na qual presumese incluído o leitor, a história a reforça para garantir sua plausibilidade e sua verossimilhança, um estereótipo indesejável que não contribui para o entendimento da atividade científica como a conhecemos hoje, isto é, algo que se faz em comunidade.

Aqui é importante e oportuno ponderar que, na época em que se passa a história, século III A. C., não existia a ciência na forma como hoje a conhecemos. O termo ciência passou a ser utilizado somente após Galileu, com o estabelecimento do procedimento experimental como uma etapa fundamental do método científico, característico das ciências naturais. Portanto, em princípio, não se poderia falar em cientistas, mesmo que reconheçamos que muitos dos grandes pensadores da Antiguidade possuíam, como objetivos, entender, descrever e explicar os fenômenos naturais e o mundo que os cercava. Considerações como essas são importantes, pois permitem apreciar a possibilidade de se trabalharem, junto com esta narrativa, aspectos da história da própria atividade científica.

\section{O que as narrativas podem nos informar sobre a Natureza da Ciência}

A discussão acima enfatiza como a narrativa pode contribuir, ou não, para facilitar o estabelecimento de relações entre os conceitos e alguns fenômenos. À primeira vista, pode parecer que o único valor de tais histórias é o seu caráter anedótico, ou mesmo uma boa motivação para iniciar o estudo de determinados conceitos. No entanto a mesma discussão nos chama atenção sobre como as narrativas nos contam um pouco sobre a ciência, sobre a sua natureza: quem são as pessoas envolvidas no fazer ciência, a que e a quem ela serve, quais os processos envolvidos nesta atividade etc. Uma análise mais cuidadosa revela, ainda, que as narrativas também permitem refletir sobre os processos da ciência. O episódio de Arquimedes com a banheira é bastante exemplar nesse sentido, e problematiza uma questão importante, presente na etapa da resolução das narrativas analisadas: o papel do acaso na construção das idéias científicas. Estava Arquimedes tomando banho quando, não se sabe exatamente como, ou por que processo, percebeu que a água que entornava da banheira poderia the dar a solução para um problema específico. Na realidade, este fato era conseqüência de uma propriedade geral dos materiais, até aquele momento, ainda ignorada. Na busca de uma solução para um determinado problema, Arquimedes acabou por descobrir uma propriedade geral que, se fos- 
se verdadeira, poderia ser utilizada na solução do problema que ele tentava resolver. Algumas narrativas de episódios da História da Ciência destacam como importantes descobertas científicas aconteceram quando menos se esperava: no banho (de Arquimedes), no sonho (de Kekulé), nos restos de matéria orgânica que repousavam sobre a mesa (de Fleming), além de vários outros. Até que ponto descobertas como essas são meramente produtos do acaso? Ou seja, será que foi somente a observação da água que derramava da banheira que deu a Arquimedes a solução do problema que procurava? Aparentemente, pode-se pensar que sim. Mas se assim de fato foi, por que a brilhante idéia ocorreu somente a Arquimedes, e não a outra(s) pessoa(s)? Somente Arquimedes teria observado (ou percebido) que, à medida que mergulhava na banheira, um pouco de água transbordava? Todas essas perguntas podem iniciar uma discussão que obriga os alunos a pensarem um pouco sobre o processo desta descoberta.

Nas narrativas analisadas, pode-se, ainda, ter a falsa idéia de que as conclusões às quais Arquimedes chegou seriam explicadas pelo fato de ele ser um gênio, sábio, inventor consagrado, de grande popularidade junto ao rei. Se não houver uma interferência do professor, no sentido de estimular e ajudar a alunos a fazerem uma reflexão mais aprofundada sobre a história que acabaram de ler, colocando questões como as anteriormente apresentadas, esta falsa idéia acabará prevalecendo. Em outras palavras, as descobertas por acaso na Ciência têm algo mais do que uma conspiração do destino em favorecer algumas personalidades dandolhes glória e fama eternas. Existe um esforço por parte destas que, conjugado a um pouco de sorte, lhes coloca o fenômeno casual no momento certo (quando elas têm algo lhe ocupando a mente) e lhes permite perceber algo que, para a maioria das pessoas, passa desapercebido. Usando as palavras de Louis Pasteur, o inventor da pasteurização e da vacina anti-rábica: “o acaso só favorece a mente preparada". De qualquer forma, como foi dito anteriormente, esta história em particular não permite a discussão de um aspecto fundamental do desenvolvimento da atividade científica, isto é, seu caráter de construção coletiva. Aqui vemos, mais uma vez, a necessidade de mediações por parte do professor na leitura destes textos.

Outro ponto importante a considerar, nas diferentes versões para a história de Arquimedes e a coroa do Rei Hierão, é a descontinuidade entre duas situações completamente distintas e sem nenhuma relação aparente: a água entornada durante o banho e o problema da coroa. Qualquer especulação sobre essa descontinuidade, porque na realidade tudo o que se afirma no sentido de completar esta lacuna é mera especulação, remete a uma reflexão sobre, pelo menos, dois recursos muito utilizados na ciência: o papel da imaginação e o uso do pensamento analógico. Ao se deparar com um fenômeno desconhecido, e cuja descrição representa um desafio para os cientistas ou mesmo um problema cuja solução é ignorada, uma das primeiras atitudes que se toma frente ao mesmo é imaginar, especular em cima da situação apresentada. É basicamente um exercício mental, que exige alguma concentração. Em outras palavras, a imaginação é um momento da atividade científica, e que muitos ignoram. As várias ações que integram a atividade científica, sejam elas a classificação de seres e objetos em classes ou grupos, o desenvolvimento de teorias que descrevem e explicam os fenômenos, ou o desenvolvimento de testes para as teorias e modelos, requerem do ser humano muita observação, além de criatividade e imaginação. É necessário criar modelos, imaginar razões que podem estar por trás de determinados comportamentos observados na natureza, ou como podem ser agrupados os seres, objetos e fenômenos. e assim por diante. 
A primeira das narrativas analisadas explicita que "o problema não me saiu da cabeça". Como realmente Arquimedes imaginou que aquele problema que não lhe saía da mente se relacionava com a água que entornou da banheira, é algo que nunca saberemos, mas a história nos chama atenção para uma possibilidade interessante: a de que a imaginação pode desempenhar um papel muito importante no desenvolvimento e na construção das explicações e idéias em ciência.

As histórias da ciência contadas nos livros didáticos, em geral, ignoram este momento fundamental da atividade científica: a imaginação. Modelos e teorias são antes inventados do que descobertos. Eles são frutos da mente humana. A natureza não nos brindou com um manual de instruções, pronto, à espera para ser descoberto, no qual se encontram todas as propriedades dos seres que dela fazem parte e como ela funciona. A construção desse "manual" é tarefa que cabe a nós, seres humanos, usando nossas capacidades intelectuais de observação, imaginação, dedução lógica, entre muitas outras. Nas palavras de Einstein, "as leis físicas são criações livres da mente bumana".

Além do papel da imaginação na atividade científica, esta história remete a um outro recurso muitas vezes utilizado na ciência, e não explicitado nas narrativas analisadas: o uso do pensamento analógico. A analogia utilizada neste caso é a seguinte: assim como o corpo de Arquimedes, mergulhado na água, derrama um pouco desta, ou seja, desloca água, analogamente, é razoável, como primeira aproximação, supor que qualquer outro corpo (inclusive uma coroa) mergulhado na água também desloque um pouco deste líquido.

A analogia é um recurso muito utilizado, inclusive, no ensino de Ciências. Ele é útil, pois nos permite tentar entender novas situações, por comparação a situações já bem compreendidas. É claro que é um recurso inicial, pois, em princípio, comparam-se situações diferentes, que têm algo em comum, mas que, na maioria dos casos, possuem diferenças. Entender a nova situação inclui perceber em que e por que a nova situação se diferencia da anterior, utilizada para comparação.

No momento em que uma analogia vem à mente pela primeira vez, não se tem certeza se ela está ou não correta, se é ou não adequada; e, na falta de conhecimentos teóricos mais aprofundados (caso de Arquimedes), só existe um meio de se ter certeza: testando. Uma vez descoberta que a analogia está correta, é necessário imaginar meios de usá-la para resolver o problema. Mais uma vez, a imaginação está presente.

Esta é uma discussão rica, esclarecedora e desmitificadora da Ciência: ela esclarece que não é num passe de mágica, de repente, que uma teoria, um modelo, ou mesmo a solução para um problema nasce na mente de um cientista. Esta discussão ajuda a esclarecer que não basta a simples observação dos fatos para se chegar às conclusões. Da observação às conclusões, é necessário percorrer um longo caminho, e, no meio deste, certamente se encontra a imaginação.

Uma outra reflexão que pode ser feita com base em episódios semelhantes, é a de que a Ciência permite redescrever os problemas usando-se parâmetros, de alguma forma, mensuráveis. Uma maneira de se fazer isto é levantando hipóteses: será que a quantidade de água deslocada é sempre a mesma? Será que ela depende do corpo que se mergulha na água? Se depender, depende do quê? Do tamanho? Do peso? Do material? Do formato? Cada uma destas perguntas refere-se a uma variável que pode ou não ser determinante na solução do 
Ribeiro, R. M. L.; Martins, I.

problema. O levantamento destas hipóteses é uma tentativa de redescrever o problema da seguinte maneira: "existe alguma relação entre a quantidade de água derramada por um sólido submerso na mesma e a composição do referido objeto?”

\section{Conclusão}

Em resumo, com base na análise de um caso exemplar, procuramos apontar para algumas possibilidades de se utilizarem narrativas como recurso no ensino das Ciências Naturais, enfatizando sua adequação para trazer à tona uma discussão, muitas vezes negligenciada, sobre aspectos relacionados à natureza da ciência. Análises como esta exploram um recurso, que em colaboração com outras abordagens e práticas, podem contribuir para ampliar o leque de alternativas pedagógicas disponíveis ao professor em sala de aula.

\section{Referências}

ANDREWS, R. (Ed.). Narrative and Argument. Buckingham: Open University Press, 1989.

BARBOSA-LIMA, M. C. A.; ALVES, L. A.; LEDO, R. A. G. Una propuesta: enseñar Física a niños de grados elementales. Enseñanza de las Ciencias, Barcelona, v. 15, n. 2, p. 273-277, 1997.

BRASIL. Diretrizes Curriculares Nacionais para o Ensino Médio. Parecer CEB n. 15/98, aprovado em $1^{\circ}$ de junho de 1998. Diário Oficial da União, Poder Executivo, Brasília, DF, 2 de jun. 1998, p. 1-45, 1998.

BRUNER, J. La educacion, puerta de la cultura. Madrid: Aprendizaje Visor, 1997. Acts of meaning. Cambridge: Harvard University Press, 1990.

Actual minds, possible words. Cambridge: Harvard University Press, 1986.

CORTAZZI, M. Narrative analysis. London: The Falmer Press, 1993.

DOLL JR., W. E. Currículo: uma perspectiva pós moderna. Porto Alegre: Artes Médicas, 1997.

EDWARDS, D. Discourse and cognition. London: Sage, 1997.

EGAN, K. An imaginative approach to teaching. San Francisco: Jossey-Bass, 2005.

Mentes educadas: cultura, instrumentos y formas de comprensión. Barcelona:

Paidós, 2000. 
O potencial das narrativas como recurso para o ensino...

GALIAZZI, M. C. et al. Narrar as histórias sobre o ser professor para constituir professores em formação. In: NARDI, R.; BORGES, O. N. (Orgs.). ENCONTRO NACIONAL DE PESQUISA EM EDUCAÇÃO EM CIÊNCIAS, 5., 2005, Bauru. Atas... Bauru, 2005. CD-ROM.

GALVÃO, C. Narrativas em Educação. Ciência \& Educação, Bauru, v. 11, n. 2, p. $327-$ 345, 2005.

GUIMARÃES, L. A.; FONTE BOA, M. Física para o Segundo Grau - Mecânica. São Paulo: Harbra, 1998.

LABOV, W. The transformation of experience in narrative syntax. In: LABOV, W. (Ed.)

Language in the inner city. Philadelphia: University of Pensnsylvania, 1972. p. 219-247.

MARTINS, I. Analisando livros didáticos na perspectiva dos estudos do discurso: compartilhando reflexões e sugerindo uma agenda para a pesquisa. Pro-Posições, Campinas, v. 17, n. 1, p. 117-136, 2006.

MARTIN, B. E.; BROUWER, W. The sharing of personal science and the narrative element in science education. Science Education, v. 75, n. 6, p. 707-722, 1991.

MÁXimO, A.; ALVARENGA, B. Curso de Física. 3. ed. São Paulo: Harbra, 1992. v. 1.

MILLAR, R.; OSBORNE, J. Beyond 2000: science for the future. London: King's College. 1998.

MILNE, C. Philosophically correct science stories? Examining the implications of heroic science stories for school science. Journal of Research in Science Teaching, v. 35, n. 2, p. 175-87, 1998.

NORRIS, S. et al. A theoretical framework for narrative explanation in science. Science Education, v. 89, n. 4, p. 535-563, 2005.

OGBORN, J. et al. Explaining science in the classroom. London: Open University Press, 1996.

PARANÁ, D. N. Física. 4. ed. São Paulo: Ática, 1995. v. 1.

RIBEIRO, R. M. L. Uma análise do potencial das narrativas no ensino de ciências. 2000. 100f. Dissertação (Mestrado) - Faculdade de Educação, Universidade Federal de Minas Gerais, Belo Horizonte, 2000.

VILARES GANCHO, C. Como analisar narrativas. 4. ed. São Paulo: Ática, 1997.

YAMAMOTO, K.; FUKE, L. F.; SHIGEKIYO, C. T. Os alicerces da Física. 12. ed. São Paulo: Saraiva, 1998. v. 1.

Artigo recebido em janeiro de 2007 e aceito em agosto de 2007. 